\title{
Determination of Sensitivity of the Winter Wheat Crop to Meteorological Factors by DAISY Model
}

\author{
Mahir Aydın', İrem Özmen ${ }^{1}$, Nilcan Altınbaş ${ }^{1 *}$, Barış Çaldağ ${ }^{1}$, Levent Şaylan $^{1}$ \\ ${ }^{1}$ Istanbul Technical University, Faculty of Aeronautics and Astronautics, Department of Meteorological \\ Engineering, Istanbul, TURKEY \\ *akatas@itu.edu.tr
}

\begin{abstract}
Climate change or climate variability has always pose a risk for sustainable agricultural production. Changes in meteorological factors may have different effects on different phenological stages of crops. For this reason, not only the quantitative change of meteorological factors but also the temporal variation of these factors' effects of crop growth and yield should be investigated. In this study, DAISY crop growth simulation model was used to analyze the sensitivity of winter wheat plant to meteorological factors during flowering period. In this context, the effect of changes in temperature, rainfall and total solar radiation during the flowering period has been examined. Key words: Climate change, Crop growth, Crop yield.
\end{abstract}

\section{INTRODUCTION}

The impact of meteorological factors on the management of the agricultural production process is crucial. The preliminary determination of these factors in terms of crop yield has a great importance socioeconomically. For this reason, it is anticipated that researches have been concentrated on the concept of climate change. As is the case for the whole world, the pre-determination of crop yields in Turkey, which is the agricultural country, has become a necessary process.

In this study, in which the sensitivity of the winter wheat crop yield to the effect of meteorological factors change during flowering period was examined and the yield was simulated with DAISY model using the meteorology and soil data between the years 2009 and 2010, collected from the research area of Atatürk Soil Water and Agricultural Meteorology Research Institute Directorate (41 $41^{\circ}$ '53" N, 27 $12^{\prime} 37^{\prime \prime} \mathrm{E}, 170$ asl), in Kirklareli city of Thrace Region in Turkey. Afterwards, it was tried to determine the sensitivity of the winter wheat crop to these changes with the scenarios created by the

\footnotetext{
* Corresponding author: akatas@itu.edu.tr
}

changes in the parameters of temperature, global radiation and precipitation.

\section{MATERIALS AND METHODS}

In this study all simulations were run by DAISY Crop Growth Simulation Model. The DAISY Model was developed in 1990 by Hansen in Denmark, as laboratory and field measurements for detecting nitrogen spillage from agricultural fields are expensive (Abrahamsen \& Hansen, 2000). After the model released, it has been used for many studies from past to present. For example, Hansen et al. (1991) used DAISY model to simulate nitrogen dynamics and biomass production of winter wheat at two locations. Based on validated values by experimental data, model results were satisfactory and only some minor adjustments were needed. Svendsen et al. (1995) have shown that the DAISY model can identify the main elements of crop behavior. Jensen et al. (1997) simulate soil organic carbon for long term using DAISY model. Because of overestimations of crop yields and root $\mathrm{C}$ input, some parametrizations about microbial biomass have been suggested. In another study comparing eight different crop growth models, the best performance considering yield estimation was for DAISY and DSSAT models (Palosuo et al., 2011). Manevski et al. 
(2016) used DAISY model to simulate crop production and nitrate leaching. It was suggested that field data should be integrated to the model. Salazar et al. (2017) performed DAISY model for predicting nitrogen leaching of the soil under maize in Chile. According to the results regarding soil water and $\mathrm{N}$ content in the different layers of the coarse-textured soil, coefficient efficiency showed that it is an applicable model to predict soil water and $\mathrm{N}$ dynamics.

The data required by DAISY climate model are meteorological, crop, soil and management data. In this study, these data were obtained from Kurklareli Atatürk Soil, Water and Agricultural Meteorological Research Institute by daily measurements carried out between 2009 and 2010. The measurement of the crop product yield was simulated with the help of DAISY crop growth model at first, and then the success of the model was tried to determine considering relative error calculations. The relative error formula used to determine model performance is as given in following equation.

$$
\varepsilon(\%)=\frac{\text { Measured value-Simulated Value }}{\text { Measured Value }} * 100
$$

Afterwards, scenarios containing the gradual changes of temperature, global radiation and precipitation data at flowering period of winter wheat crop were applied to determine the sensitivity of this crop to these meteorological parameters.

\section{RESULTS}

The dates of phenological stages obtained by DAISY model simulations during the growing season of winter wheat crop, and the observations noted in the experimental field of the research institute are given in with four development periods (Table 1). Noted and simulated germination and $2^{\text {nd }}$ leaf dates are very close to each other. Only 2 and 3 day difference exists, respectively. Yet, the model identified the flowering and maturity dates as nine days before than the real situation.
Table 1. Phenological stages of winter wheat crop in 2009-2010 growing season.

\begin{tabular}{lll}
\hline & Simulation & Observation \\
\hline Germination & 15.10 .2009 & 17.10 .2009 \\
$2^{\text {nd }}$ leaf & 24.10 .2009 & 21.10 .2009 \\
Flowering & 01.05 .2010 & 10.05 .2010 \\
Maturity & 14.06 .2010 & 04.06 .2010 \\
\hline
\end{tabular}

\section{Temperature Scenarios}

The crop yield obtained by the simulations is $485 \mathrm{~kg} / \mathrm{da}$ while the actual value $519 \mathrm{~kg} / \mathrm{da}$. The model underestimate the yield when considering real temperature condition. Relative error was calculated as $6.53 \%$.

In order to analyze the sensitivity of winter wheat crop to temperature changes, temperature values were decreased and increased gradually (from $\mathrm{T}-5$ to $\mathrm{T}+5$ ), then crop yields were simulated again (Fig. 1). The most obvious change arises when temperature was increased by $5{ }^{\circ} \mathrm{C}$. Crop yield was estimated to be decrease by $16 \%$ for this scenario. When the temperature is decreased by $5{ }^{\circ} \mathrm{C}$, the decrease of crop yield was estimated as $6.3 \%$. It has been assigned that the crop yield decrease gradually when the temperature has increased or decreased. All scenarios predicted reduced crop yield except the scenarios which temperature is decreased by $1^{\circ} \mathrm{C}, 2^{\circ} \mathrm{C}$ and $3^{\circ} \mathrm{C}$. For these three condition, it is estimated that the crop yield will increase by $1.6 \%, 2.3 \%$ and $1.2 \%$, respectively.

\section{Radiation Scenarios}

Global solar radiation rates were changed as decrease and increase by $5 \%$ and the changes in crops yields were examined (Figure 2). While the reduction of global radiation rates have a positive effect on crop yield, the increase has a negative effect. The maximum 
crop yield $(\sim 550 \mathrm{~kg} / \mathrm{da})$ is reached when global solar radiation is reduced by $30 \%$.

According to the model results, the decrease of global solar radiation in flowering period will affect the yield positively. Moreover, decrease of radiation by $40 \%$ has created favorable condition for yield to be increased.
When oscillations of the simulated crop yield values are considered, range between the maximum and the minimum estimated crop yield values is approximately 150 $\mathrm{kg} / \mathrm{da} .50 \%$ decrease or increase of global solar radiation cause crucial changes of crop yields.

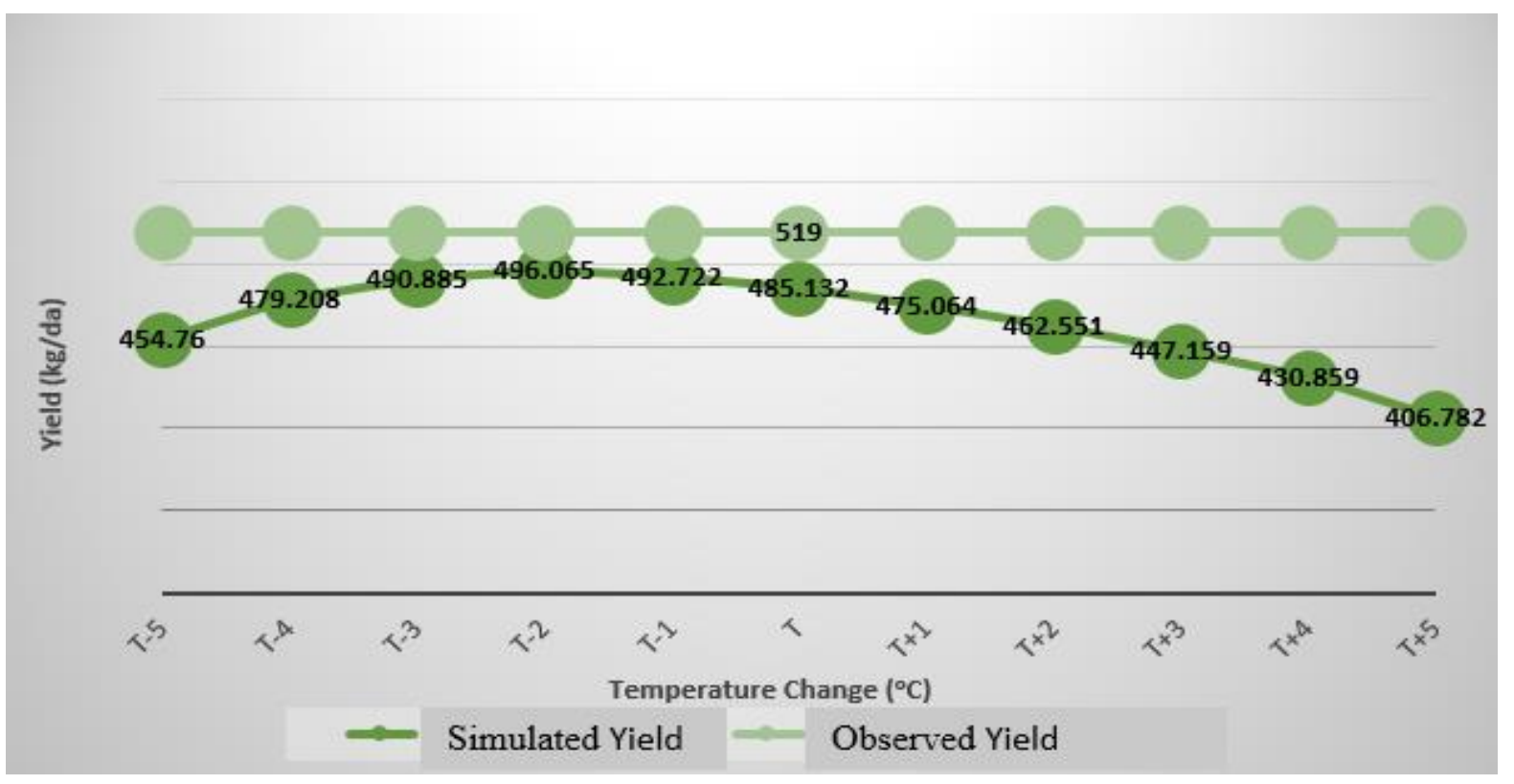

Figure 1. Temperature Change-Yield Relation.

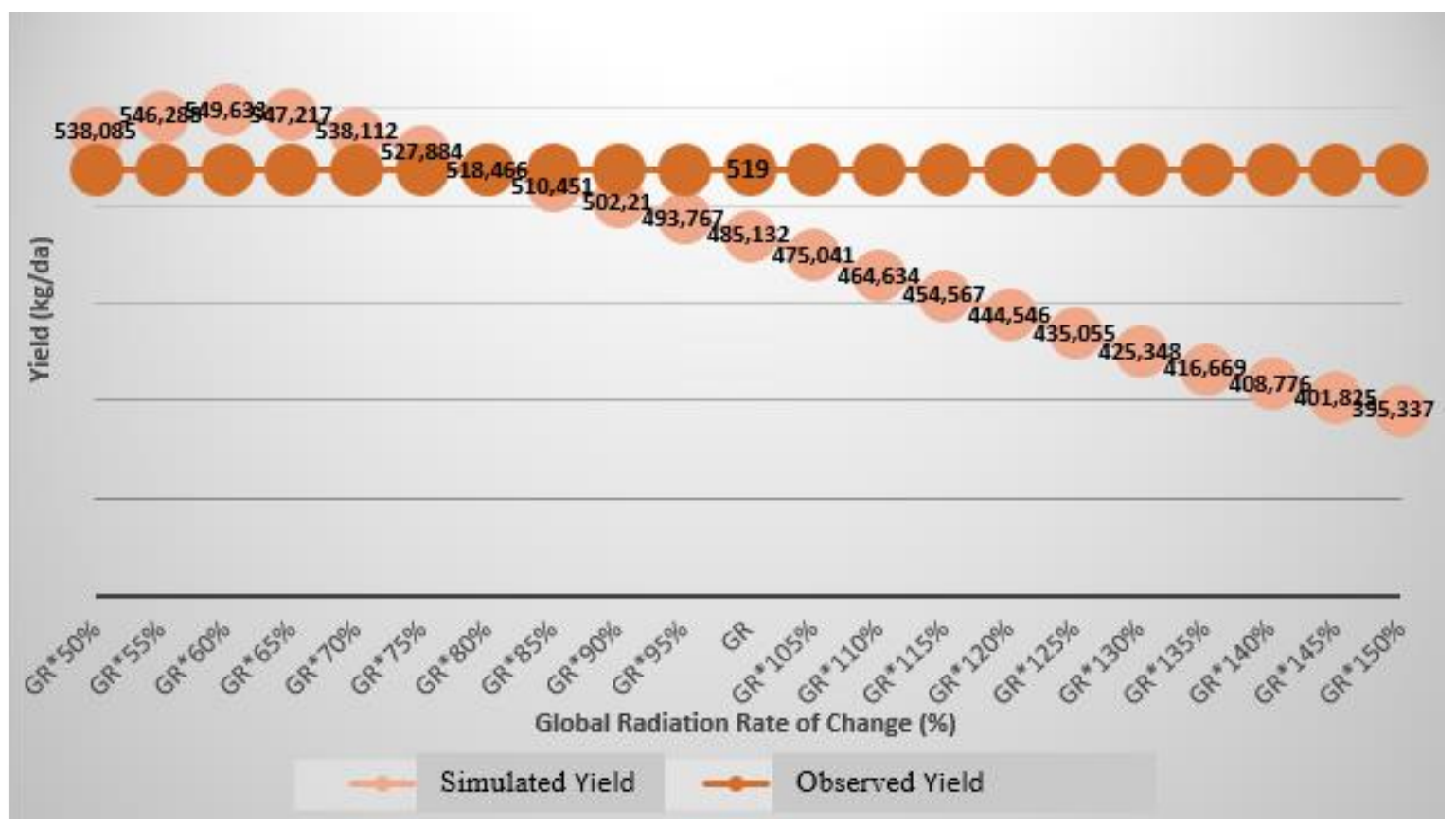

Figure 2. Global Radiation Change-Yield Relation.

Precipitation Scenarios
Changes of precipitation rates affect crop yields proportionally. Simulations have 
showed that the decrease of precipitation always resulted in reduce in crop yield, and vice versa (Figure 3 ). The maximum yield is temperature may cause reduction of yields. In the case of $2^{\circ} \mathrm{C}$ declines in temperature, the yield increases most by $2.3 \%$. After $3{ }^{\circ} \mathrm{C}$ decline, yield values have dropped again.

According to the radiation scenarios, if radiation rates increase up to 1.5 times, crop

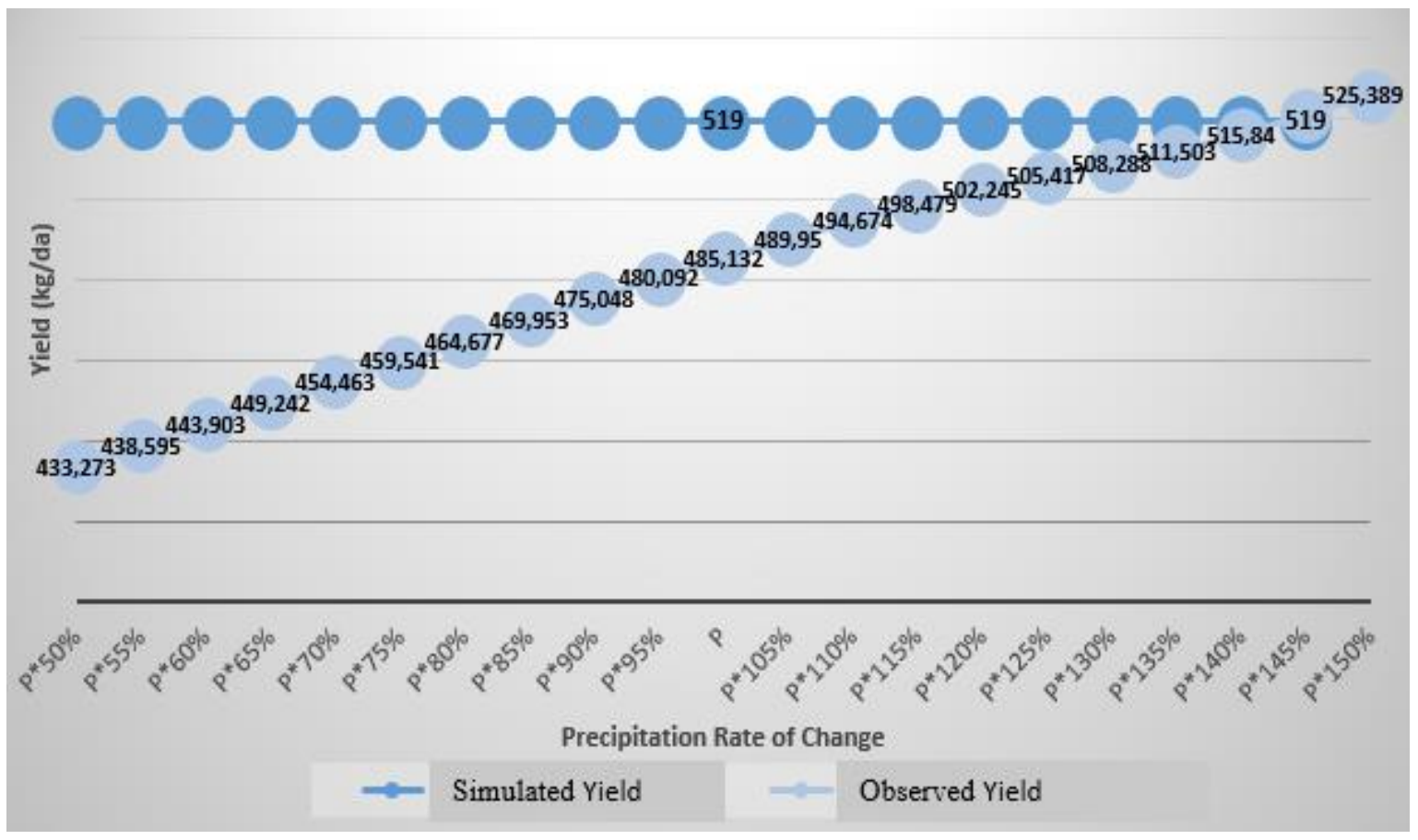

Figure 3. Global Radiation Change-Yield Relation.

reached when precipitation is increased by $150 \%$. The increase of crop yield is $8.3 \%$ in this situation. Besides, yield is decreased by $\% 10.7$ when precipitation is reduced by half. Although fluctuation of the simulated values is not as much as global radiation scenario results, it can be clearly noticed that precipitation has a significant effect on yield.

\section{CONCLUSION AND DISCUSSION}

In this study, it was aimed to investigate the possible effects of meteorological parameters on winter wheat yield during flowering period by using DAISY crop growth simulation model and the data collected from experimental field in Kirklareli.

When considering temperature scenarios, model simulations showed that increases in yields will decrease dramatically. On the contrary, decrease of radiation increases the yield. Especially, while global radiation decrease is $40 \%$, maximum yield value has been estimated.

Considering precipitation scenarios which includes the increases always have resulted in increased yields. It was determined that decreases in precipitation rates affect winter wheat yields negatively.

The barely variation of estimated precipitation values by different scenarios can be attributed to the low amount of precipitation during the flowering period of winter wheat.

In this kind of studies containing fieldwork, some spatial coefficients which are suitable for location should be included to the model. As a future work, finding and using crop coefficients for winter wheat and other crops grown in Kirklareli have been planned to increase the model performance. In addition, all scenarios applied in the study will be 
combined in order to understand optimal conditions for crop growing and increase the yield.

\section{ACKNOWLEDGEMENTS}

We would like to thank to Atatürk Soil Water and Agricultural Research Institute Directorate employees who help us during the field studies.

\section{REFERENCES}

Abrahamsen, P. and Hansen S. (2000). Daisy: an open soil-crop-atmosphere system model. Environmental Modelling \& Software, 15, 313 - 330.

Hansen, S., Jensen, H. E., Nielsen, N. E. et al. (1991). Simulation of nitrogen dynamics and biomass production in winter wheat using the Danish simulation model DAISY. Fertilizer Research, 27: 245.

Manevski, K., Børgesen, C. D., Li, X., Andersen, M. N., Abrahamsen, P., Hu, C., Hansen, S. (2016). Integrated modelling of crop production and nitrate leaching with the Daisy model, MethodsX, pp. 350-363.

Palosuo, T., Kersebaum, K. C., Angulo, C. et al. (2011). Simulation of winter wheat yield and its variability in different climates of Europe. A comparison of eight crop growth models. European Journal of Agronomy, 35, 103-114.

Salazar, O., Nájera, F., Tapia, W., Casanova, M. (2017). Evaluation of the DAISY model for predicting nitrogen leaching in coarse-textured soils cropped with maize in the Mediterranean zone of Chile. Agricultural Water Management, 182, 77-86. 